\title{
Decision-Making by Precedent and the Founding of American Honda (1948 - 1974)
}

\section{Citation}

Casadesus-Masanell, Ramon, and John Heilbron. "Decision-Making by Precedent and the Founding of American Honda (1948 - 1974)." Harvard Business School Working Paper, No. 17-016, August 2016.

\section{Permanent link}

http://nrs.harvard.edu/urn-3:HUL.InstRepos:30838903

\section{Terms of Use}

This article was downloaded from Harvard University's DASH repository, and is made available under the terms and conditions applicable to Open Access Policy Articles, as set forth at http:// nrs.harvard.edu/urn-3:HUL.InstRepos:dash.current.terms-of-use\#OAP

\section{Share Your Story}

The Harvard community has made this article openly available.

Please share how this access benefits you. Submit a story.

Accessibility 


\section{Decision-Making by Precedent and the Founding of American Honda (1948 - 1974)}

Ramon Casadesus-Masanell John Heilbron

Working Paper 17-016 


\title{
Decision-Making by Precedent and the Founding of American Honda (1948 - 1974)
}

\author{
Ramon Casadesus-Masanell \\ Harvard Business School \\ John Heilbron \\ Harvard Business School
}

Working Paper 17-016 


\title{
Decision-Making by Precedent and the Founding of American Honda (1948 - 1974)*
}

\author{
Ramon Casadesus-Masanell ${ }^{\dagger} \quad$ John Heilbron ${ }^{*}$
}

August 2016

\begin{abstract}
American Honda was founded in 1959 as a wholly owned subsidiary of the Honda Motor Company to facilitate sales and distribution in the United States. The details of American Honda's early history have long served as evidence in debates among scholars and practitioners about the managerial determinants of the subsidiary's success. In particular, it is debated whether American Honda operated according to a deliberate or emergent strategy, i.e. whether or not strategic decisions made in the States conformed to the intentions of upper management. This paper presents evidence that Kihachiro Kawashima, President of American Honda from 1959 to 1965, made important decisions according to precedent set by his boss and mentor, Honda's chief strategist, Takeo Fujisawa. It presents further evidence that these decisions may have contributed to the recovery of American Honda from its sales crisis during the late 1960s and its continued success thereafter. Addressing ourselves to concepts in the management literature, we argue that strategy realized by the appeal of subordinates to the historical precedent of their superiors defies categorization as deliberate or emergent.
\end{abstract}

\footnotetext{
${ }^{*}$ We thank Honda Motor Company for access to recorded interviews of Kihachiro Kawashima from a $199850^{\text {th }}$ anniversary retrospective and oral history of Honda Motor Company. This research benefited greatly from an interview with Takayuki Kobayashi, the sole surviving member of the original team sent by Takeo Fujisawa to the United States in 1959 to found American Honda. We are thankful to Kobayashi-san for his willingness to share his views and experiences. We also thank the HBS's Japan Research Center, and Nobuo Sato in particular, for assistance in translating interviews and original historical documents. We gratefully acknowledge financial support from the HBS Division of Research.

† Harvard Business School. Email: rmasanell@hbs.edu

^Harvard Business School. Email: jheilbron@hbs.edu
} 


\section{[I] Introduction: Historical Precedent, Hypothetical Intentions, and Strategic Decision-Making}

The production and distribution of goods in a firm is commonly overseen by a hierarchy of management. Managers are employed by the owners of a firm but responsible for ensuring the productivity of their fellow employees rather than being charged with manipulation of goods themselves. The hierarchy is an established order between the offices held by various managers. A given manager is superior to several of her fellow employees in that she is entitled to reports on their activities, is responsible to a degree for their success or failure, has influence over their continued tenure or promotion within the organization, and holds decision-making authority relative to choices they face on the job.

The official hierarchical structure of a firm notwithstanding, decision-making within these organizations is very often frenetic. Competing visions of a firm's future may vie politically to determine choice outcomes. Self-interested employees may favor choices not aligned with the interests of a firm's owners. Information may be available in only limited amounts or only to particular parties within the firm. Recommendations, consultations, directives but also suspicions, misunderstandings and hubris - in short, the many variants of orderly and failed collaboration - ensure the difficulty of identifying, in the real world, where strategies hail from in the hearts and minds of the people tasked with managing a company.

What is the origin of the intentions that are realized in a firm's strategy? Past research has attributed decision outcomes to intentions of different parties within the firm. Early historians and management scholars evoked a top-down process in which choices are made according to the intentions of upper management. ${ }^{1}$ Such work followed an economic tradition in which firms are conceived as authority structures allowing managers to issue commands subsequently implemented by their subordinates. ${ }^{2}$ Later work observed that, the authority of upper management notwithstanding, strategic decisions could be realized absent or even contrary to their intentions. These scholars argued that strategic

\footnotetext{
${ }^{1}$ Chandler, Strategy and Structure; Hambrick and Mason, "Upper Echelons"; Ansoff, Strategic Management; Andrews, The Concept of Corporate Strategy.

${ }^{2}$ Coase, "The Nature of the Firm"; Williamson, "Hierarchical Control and Optimum Firm Size."
} 
choices were made according to the express intentions of subordinates, notions passed up the hierarchy in pursuit of approval or funding. ${ }^{3}$

This paper elaborates a qualitatively different origin for strategic intentions. We argue, by close examination of American Honda's history, that strategic choices may be guided - at root - by hypothesized intentions. Among the alternatives comprising a choice, an intention is the alternative marked for selection by the will of a particular agent. Agent A may well reveal an intention by expressing the contents of her will. But Agent B may equally hypothesize the intention of Agent A by marking an alternative for selection and invoking precedent set by Agent A to suggest the alternative is plausibly her preference. We demonstrate empirically that Kihachiro Kawashima, the President of American Honda, made important strategic decisions by following the precedent set by his boss and former mentor, Honda's chief strategist, Takeo Fujisawa. That is to say, Kawashima's own intentions in governing American Honda originated in a hypothesis about what Fujisawa's might have been.

By describing the influence of hypothesized intentions, this paper challenges a long-standing dichotomous characterization of strategy as either deliberate or emergent. For Mintzberg, deliberate strategy consists of choices 'realized as intended' and emergent strategy consists of choices 'realized...in the absence of intention'. It may seem straightforward to assume, as in these definitions, that managerial intentions are either present or absent. But in the case of Honda, Fujisawa - the ranking officer of the firm - did not know about various choices encountered in America and certainly could form no intention regarding the choice itself. Kawashima made his decision, however, by observing precedent set by Fujisawa and posing a plausible and hypothetical intention on his behalf. That is to say, the management intentions at play in the case of Honda were neither present nor absent but fictive, a creative construction of both historical reality and imagination. Mintzberg's simple distinction between deliberate and emergent does not accommodate such a case.

\footnotetext{
${ }^{3}$ Bower, "Chapter 2: Findings"; Burgelman, "A Process Model of Internal Corporate Venturing in the Diversified Major Firm."; Mintzberg, "Patterns in Strategy Formation"; Mintzberg and Waters, "Of Strategies, Deliberate and Emergent."

${ }^{4}$ Mintzberg and Waters, "Of Strategies, Deliberate and Emergent."
} 
By identifying the guiding influence of historical precedent and hypothesized intentions, this study emphasizes the social (cf. rational or behavioral) character of strategic decision-making.

Kawashima makes decisions by channeling his former mentor rather than, say, by unaffected analysis of the business environment or uncultivated instinctual response. This is not a novel contribution and, indeed, the literature on 'Strategy as Practice' stresses that agents of the firm are embedded in social and historical context. ${ }^{5}$ However, that literature ${ }^{6}$ sometimes cites existing studies of early decision-making at American Honda as examples of such embeddedness - i.e. of "how agents spontaneously...draw on the particular socio-cultural norms and material resources available to respond to...practical situations". ${ }^{7}$ This citation is misleading because, as elaborated in Section [III], prevailing interpretations of American Honda stress the opportunism of its officials, not their inheritance of management techniques. The present analysis of the Honda case provides an interpretation of decision-making with explicitly social origins.

In general, a detailed historical case study provides several advantages for understanding strategic decision-making. First, case studies provide rich empirical detail that allows for an audit of decisionmaking protocols. In Section [IV], this study identifies and rejects possible decision-making protocols in favor of 'appeal to precedent' because they lack explanatory power. Second, there are some hypotheses that cannot be verified without investigation of the historical record. Understanding the history of the Honda Company generally (Section [V]) supported Kawashima's claims about his approach to managing American Honda specifically (Section [VI]). Finally, when discussing history, developments that take place after managerial choices are already available as past events. This allows us, in Section [VII], to consider the effects of managerial choices on organizational performance over time.

The Honda Motor Company - in particular - is appropriate subject matter for a discussion of strategic decision-making. As reviewed in Section [III], the company has provided the historical evidence for considerable debate over whether strategy in real-world organizations conforms to the intentions of

\footnotetext{
${ }^{5}$ Whittington, "Completing the Practice Turn in Strategy Research.”; Jarzabkowski, "Shaping Strategy as a Structuration Process."

${ }^{6}$ Chia and Holt, "Strategy as Practical Coping: A Heideggerian Perpective."; Tsoukas, "Practice, Strategy Making and Intentionality: A Heideggerian onto-Epistemology for Strategy as Practice."

${ }^{7}$ Tsoukas, "Practice, Strategy Making and Intentionality: A Heideggerian onto-Epistemology for Strategy as Practice."
} 
upper managers or emerges according to the intuition of subordinates. The case was originally of interest to industry actors, but later received attention in management journals and business school case studies. Richard Pascale's short history of the founding of American Honda is cited in discussions of Japanese management, ${ }^{8}$ managerial improvisation, ${ }^{9}$ and the management of strategic opportunities. ${ }^{10}$ Pascale and Evelyn Christiansen created a case study of the Honda Motor Company for the Harvard Business School in the $1980 \mathrm{~s},{ }^{11}$ which was revived with considerable conceptual clarity by Jan Rivkin in $2003 .{ }^{12}$

To write this history of American Honda, we consulted scholarly literature and conducted original historical research. Though management literature covered many of the basic facts of the Honda case, it was helpful to consult historical literature as well, given its emphasis on robust presentation of detail. We identified and interviewed ${ }^{13}$ Takayuki Kobayashi, the sole surviving member of the original team sent by Fujisawa to the United States in 1959 to found American Honda. We reached out to the Honda Motor Company, who supplied us with recorded interviews of Kihachiro Kawashima from a 1998 retrospective and oral history. We interviewed Musselman Honda and Dreyer Honda, two of the earliest Honda dealerships in the United States to learn more about the company's cash-on-delivery policy. We consulted newspaper and magazine clippings, Honda's corporate reports from the 1960s, and data available through Harvard Business School case studies originally supplied by the Japanese Automobile Manufacturers Association (JAMA).

In Section [II], we describe the basic facts of the American Honda case: its success in consumer markets ([IIA]) and management decisions made in the early years ([IIB]). We accept BCG's explanation

\footnotetext{
${ }^{8}$ Kato et al., "Types of Upward Communication and Organizational Characteristics in Japanese Firms."

${ }^{9}$ Vera and Crossan, "Improvisation and Innovative Performance in Teams"; Baker, Miner, and Eesley, "Improvising Firms: Bricolage, Account Giving and Improvisational Competencies in the Founding Process"; Moorman and Miner, "Organizational Improvisation and Organizational Memory"; Miner and Robinson, "Organizational and Population Level Learning as Engines for Career Transitions."

${ }^{10}$ Denrell, Fang, and Winter, "The Economics of Strategic Opportunity"; Papadakis, Lioukas, and Chambers, "Strategic Decision-Making Processes: The Role of Management and Context"; Woolridge and Floyd, "The Strategy Process, Middle Management Involvement, and Organizational Performance."

${ }^{11}$ Christiansen and Pascale, "Honda (A)"; Christiansen and Pascale, "Honda (B)"; Christiansen and Pascale, "Honda (A) and (B) Teaching Note."

${ }^{12}$ Rivkin, "Honda (A) and (B) Teaching Note (II)."

${ }^{13}$ Interviews and translations were conducted with the help of Harvard Business School Japan Research Center Executive Director Nobuo Sato and his assistant, Akiko Kanno. Transcripts of the interview with Kobayashi are available upon request. Notes of interviews with early Honda dealers are available. Transcripts of the Honda Motor Company's interviews with Kawashima are available pending consent from the Honda Motor Company.
} 
of the economic logic that made American Honda successful, namely the achievement of high sales volume to lower production costs. We note BCG's description of Honda's advance into market segments with larger motorcycles over time because of the role this plays in our later analysis. The primary purpose of the paper is to evaluate the decision-making protocols guiding the decisions described in [IIB] and the effects of these choices. As made clear in following sections, we break from BCG in describing how the Honda organization made decisions.

In Section [III], we revisit scholarly debate on how decisions were made within the Honda organization. We articulate the definitions of 'choice', 'strategy', 'deliberate strategy', and 'emergent strategy' as the terms are used in this paper. We then contrast our position on the decision-making process at Honda with three existing strands of literature. Some scholars characterize Honda's strategy as deliberate and others characterize it as emergent. The work of other scholars makes clear that different decisions might be alternately deliberate or emergent, making strategy as a whole difficult to classify as purely deliberate or emergent. Our tact is to suggest that individual decisions made by appeal to historical precedent defy easy classification as deliberate or emergent.

Sections [IV], [V], and [VI] substantiate the claim that decisions at Honda were made in a manner neither properly deliberate nor properly emergent. Section [IV] discusses historical evidence establishing that certain decision-making protocols, like the 'implementation of orders' or 'exploitation of short-run sales opportunity', do not explain decision outcomes. Section [V] describes evidence that a different protocol, 'appeal to historical precedent', could explain these very decisions. Section [VI] presents further evidence, some the product of original investigation, that 'appeal to historical precedent' does explain decision-making at American Honda.

Having established how decisions were made at American Honda, Section [VII] investigates the effects of these decisions. In particular, it argues that the segment advance observed by the BCG (described in [II]) was a response to changing consumer tastes that Fujisawa became aware of when managing Honda's sales crisis in 1966. Assuming the effects of Kawashima's decisions resembled the effects of Fujisawa's in Japan (discussed in [VB]), they plausibly equipped Fujisawa with better 
information about changing consumer tastes. For this reason, we hypothesize that American Honda's continued success was the result of its leaders' decision-making by historical precedent, a protocol rendering the resulting strategy neither properly deliberate nor emergent.

\section{[II] The Facts: Establishing American Honda}

Between industry reports, ${ }^{14}$ management trade papers, ${ }^{15}$ business school case studies, ${ }^{16}$ popular ${ }^{17}$ and academic histories, ${ }^{18}$ many basic facts of Honda's entrance into American markets are wellestablished. Below, we introduce the Honda Motor Company and present a stylized narrative of American Honda's early years. Much of the historical detail recounted is unoriginal because it is undisputed; the primary purpose of this paper is instead to challenge prevailing interpretations of how decision-making in the Honda organization took place. Some of the historical detail departs from traditional narratives because of empirical work we conducted to clarify, corroborate, and supplement evidence in other sources. We introduce major players and events in American Honda's early history and recount the success of the subsidiary that has so captured the attention of scholars. We then describe important decisions made and overseen by American Honda's President during the subsidiary's early years. The managerial choice is the basic unit of analysis pursued in the remainder of the paper.

\section{[A] American Honda in Context (1948-1975)}

Soichiro Honda entered a young motorcycle industry in the mid-1940s after making technical advances in piston ring design and tinkering unsuccessfully with weaving machines. ${ }^{19}$ He produced motorized bicycles for two years before founding the Honda Motor Company in 1948. In its early days, Honda Motors not only assembled and sold motorcycles but sold engines to other manufacturers as components. Motorcycles, which presented an attractive, affordable means of transportation to Japanese consumers in the aftermath of the First World War, proved an attractive business. The five years

\footnotetext{
${ }^{14}$ Boston Consulting Group, Strategy Alternatives for the British Motorcycle Industry.

${ }^{15}$ Pascale, "Perspectives on Strategy."

${ }^{16}$ Christiansen and Pascale, "Honda (A)"; Christiansen and Pascale, "Honda (B)"; Christiansen and Pascale, "Honda (A) and (B)

Teaching Note"; Rivkin, "Honda (A) and (B) Teaching Note (II)."

${ }^{17}$ Shook, "Honda Comes to America"; Brown, Honda; Sanders, Honda; Satō, The Honda Myth; Sakiya, Honda Motor.

${ }_{18}^{18}$ Otahara, "An Evolutionary Phase of Honda Motor"; Alexander, Japan's Motorcycle Wars.

${ }^{19}$ Alexander, Japan's Motorcycle Wars, 115.
} 
following the founding of Honda Motors saw a 10-fold increase in the number of motorcycle manufacturers operating in Japan. ${ }^{20}$

For all of Soichiro's inventiveness, he could be hot-headed and financially careless; he lacked business savvy in a market rapidly becoming more competitive. In Takeo Fujisawa, he found a levelheaded business partner capable of reigning in his eccentricities and guiding his inventive muse. ${ }^{21}$ When Honda threatened to refuse an award from the Emperor in recognition of his contributions to the manufacturing industry because of the requirement that he wear a suit to the ceremony, Fujisawa dug one up and convinced him to attend appropriately dressed. ${ }^{22}$ Likewise, it was Fujisawa who encouraged Honda to repurpose engine advances achieved in pursuit of excellence on the racing circuit to a more marketable motorcycle for the every-day user. ${ }^{23}$ But beyond tempering Honda's erratic behavior, Fujisawa made independent, substantive, managerial contributions to the Honda Motor Company that are explored in this paper.

The Honda Motor Company was successful during the 1950s in Japanese domestic commercial markets. During that decade, it became one of four industry leaders and saw its market share rise: 9.9\% in $1951,15 \%$ in 1954 , and $18.9 \%$ by $1957 .{ }^{24}$ For Honda and Fujisawa, ambition and success were inseparable; by the late 1950 s, they had their sights set on foreign markets. Fujisawa appointed sales representative Kihachiro Kawashima to head an exploratory committee on how best to expand internationally. ${ }^{25}$ Together with his assistant Takayuki Kobayashi, Kawashima made a reconnaissance trip in 1958 to San Francisco, Los Angeles, Dallas, New York, and Columbus. ${ }^{26}$ After they reported to Japan, Fujisawa decided that Honda would expand first into the States and he appointed Kawashima to establish and run a wholly-owned subsidiary there, American Honda. Kawashima returned to Los Angeles in June of 1959, accompanied Kobayashi, yet again, as well as another assistant. ${ }^{27}$

\footnotetext{
${ }^{20}$ Ibid., 101.

${ }^{21}$ Satō, The Honda Myth, 68.

${ }^{22}$ Sanders, Honda, 66.

${ }^{23}$ Sakiya, Honda Motor, 117.

${ }^{24}$ Otahara, "An Evolutionary Phase of Honda Motor," 120; Pascale, "Perspectives on Strategy," 52.

${ }^{25}$ Shook, "Honda Comes to America," 28.

${ }^{26}$ Pascale, "Perspectives on Strategy," 54.

${ }^{27}$ Shook, "Honda Comes to America," 30.
} 
Business in America was initially slow and uncertain. The founders of American Honda arrived in Los Angeles with 300 units divided between four classes of motorcycle - the Super Cub (50cc), the Benley (125cc), and the Dream (250cc and 350cc). By September, three months into their stay, Kawashima and his team had sold only eight units of the Dream. By the end of December, they had sold 200 units and were doing business with 15 dealers. ${ }^{28}$ They had recruited some 40 dealers by the spring of 1960, who were selling a total of 100 units a month for them, primarily the larger models. ${ }^{29}$ But these larger bikes were not designed to withstand the wear and tear imposed by American drivers. Customers began reporting clutch failure and leaking oil and Kawashima was forced to recall the faulty models to have them tested and fixed. This left him with only the Super Cub, a model which home office superiors did not expect to sell well ${ }^{30}$ and which traditional motorcycle dealers had expressed relatively little interest in to date. ${ }^{31}$

In the face of uncertainty and setbacks, Honda established itself as a leading motorcycle manufacturer in the States by the mid-1960s and maintained this position well into the 1970s. Sales climbed: American Honda sold only 1,315 motorcycles in 1960, but sold 227,600 bikes in 1965 and 441,200 in 1970. Similarly, revenue from sales in America rose from about $\$ 0.5$ million in 1960 to $\$ 77$ million by $1965 .{ }^{32}$ In the following year, having spent only eight years in the United States, American Honda supplied $63 \%$ of lightweight motorcycles to the market. ${ }^{33}$ Another eight years later, in 1974, not only did it control certain product segments to the tune of $60 \%$ market share, but it had diversified across segments to control $43 \%$ of the entire market. ${ }^{34}$

\footnotetext{
${ }^{28}$ Ibid.

${ }^{29}$ Pascale, "Perspectives on Strategy," 55; Kobayashi, Founding American Honda.

${ }^{30}$ Pascale, "Perspectives on Strategy," 55.

${ }^{31}$ Kobayashi, Founding American Honda.

${ }^{32}$ Boston Consulting Group, Strategy Alternatives for the British Motorcycle Industry.

${ }^{33} \mathrm{BCG}$ as reproduced in Pascale

${ }^{34}$ Boston Consulting Group, Strategy Alternatives for the British Motorcycle Industry, 17.
} 
Figure 1 Japanese motorcycle industry: price experience curves (1959-1974)

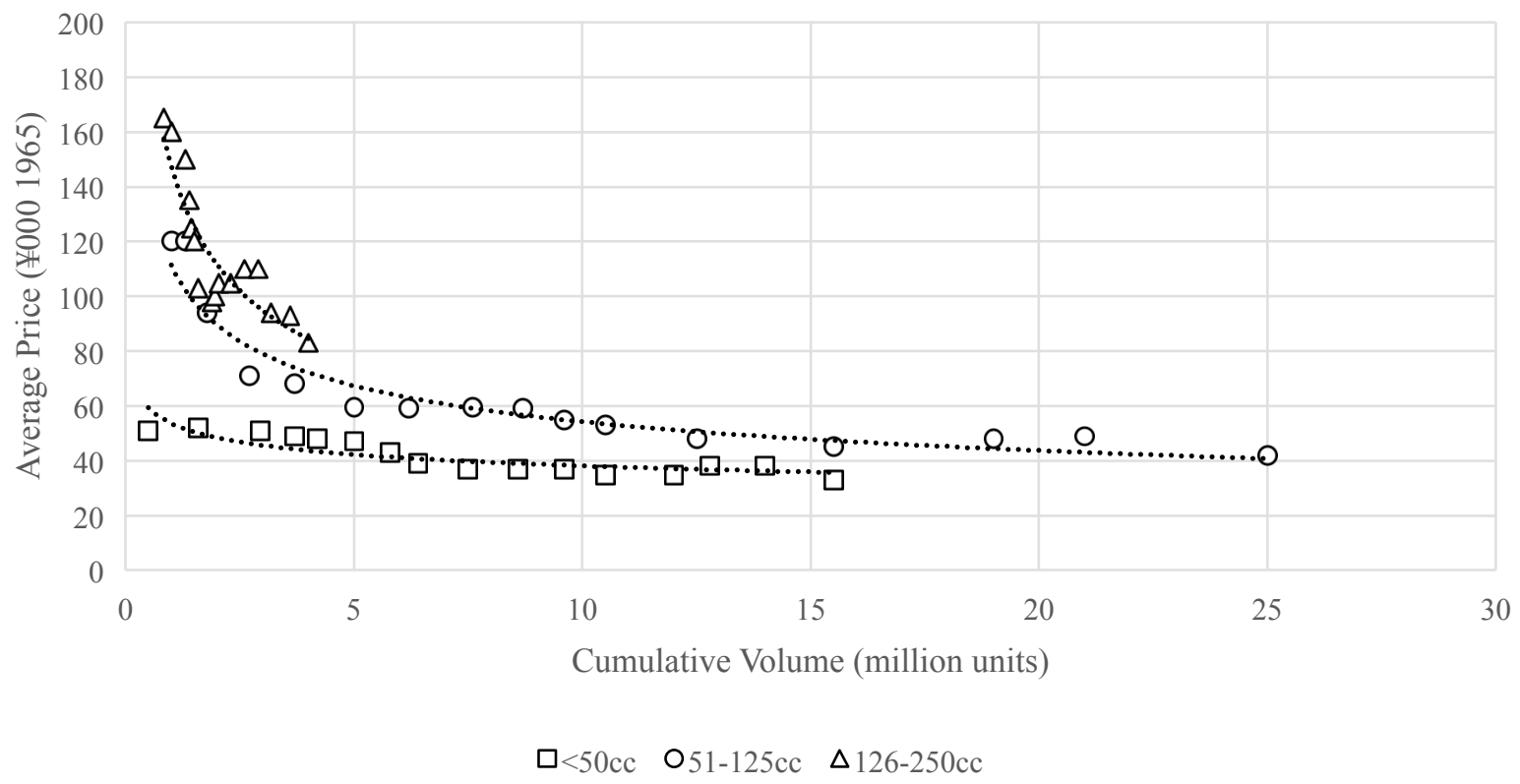

Source: Boston Consulting Group, Strategy Alternatives for the British Motorcycle Industry, 40.

Note: As the volume of Japanese motorcycles sold in the United States accumulates year-to-year, the price at which each class of motorcycle is sold decays exponentially. Substantial volumes of smaller models are observable as early as 1959.

Figure 2 Honda large bikes: price experience curves (1968-1975)

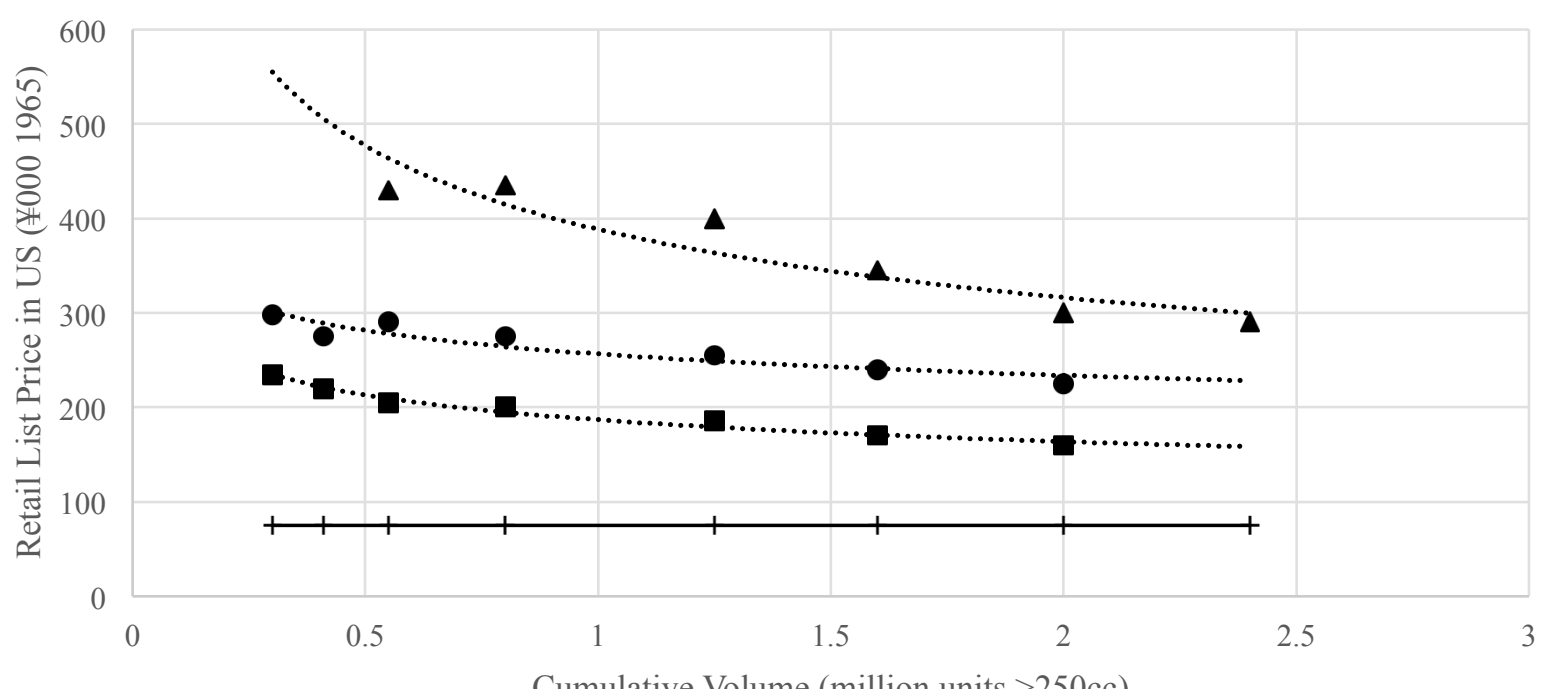

Cumulative Volume (million units $>250 \mathrm{cc}$ )

Source: Boston Consulting Group, Strategy Alternatives for the British Motorcycle Industry, 41.

Note: The price of Honda's larger models of motorcycles follows a trend of exponential decay when cumulative volume is interpreted as Honda's total output of motorcycles with an engine larger than $250 \mathrm{cc}$. Notice - in contrast to figure $1-$ that Honda begins to accumulate significant volume in large bicycles only by the late 60 s and early 70 s. Indeed, the CB450 was developed in 1965 , but the CB350 was developed in 1968 and the CB750 first came to market in the States in $1970 .^{35}$

${ }^{35}$ Brown, Honda, 29-33. 
According to the Boston Consulting Group, Honda captured the American market by achieving experience economies in a process of segment advance. High production volumes allowed Honda to achieve low production costs and eventually sell their goods for less than their rivals - explaining their growing market share within segments. Segment advance refers to the repeated application of this approach to larger classes of motorcycle, sequentially - explaining their growing market share between segments. BCG presents evidence that the average price of smaller Japanese models began to fall beginning in 1959 (figure 1). (They interpret this as indicative of underlying drops in cost.) They then describe a similar phenomenon occurring in Honda's larger models, which Honda introduced in the late 1960s (figure 2). ${ }^{36}$

[B] Important Managerial Decisions in the Early Years of American Honda (1959-1965)

It is natural to wonder what exactly management was doing amidst the rise of American Honda from obscurity to renown. Kawashima personally made and oversaw several important decisions during his early tenure as the President of American Honda. Here, we review choices crucial to understanding American Honda's history in the United States and integral to the remainder of the paper. He refused a department store who offered to sell the Super Cub, began selling the Super Cub through unconventional outlets like sporting goods stores and hunting stores, oversaw rebranding with the 'Nicest People' campaign, and stopped advancing goods to dealers prior to payment.

Around the time that Honda's larger bikes began to fail, in the spring of 1960, a department store by the name of Montgomery Ward approached Honda's sales team with an offer to sell 650 units of the Super Cub per year. ${ }^{37,38}$ Given that Honda was a young company, struggling to sell motorcycles, and

\footnotetext{
${ }^{36}$ Boston Consulting Group, Strategy Alternatives for the British Motorcycle Industry, 24.

${ }^{37}$ Pascale, "Perspectives on Strategy," 56; Kobayashi, Founding American Honda.

${ }^{38}$ It is likely that American Honda declined not only Montgomery Ward but also an offer from Sears Roebuck. In his interview with Pascale, Kawashima claims that Sears approached them with an offer to sell their motorcycles. Kobayashi, in his interview with us, did not recall Sears approaching the subsidiary in its early years. In his interview with Honda Motor representatives on the occasion of American Honda's 50 ${ }^{\text {th }}$ anniversary, Kawashima mentioned that both Sears and Montgomery Ward approached American Honda. In our assessment, Kobayashi's doubts notwithstanding, this latter recollection convincingly demonstrates that American Honda was approached not once but twice by department stores. That is, Kawashima had not mistakenly referred to an offer from Montgomery Ward as an offer from Sears.
} 
possibly amidst a widespread recall of faulty models, the offer presented a significant sales opportunity. ${ }^{39}$ Kobayashi, by this point the head of sales, learned of the offer and brought it to the attention of Kawashima. In a decision made without consulting Fujisawa, Kawashima turned down the offer. ${ }^{40}$ Kawashima began to push sales of the Super Cub despite having declined the offer of Montgomery Ward. Rather than work only through the standard motorcycle outlets, he encouraged members of his sales team to reach out to non-standard outlets. Honda motorcycles could be found at sporting goods stores, hardware stores, fishing goods stores, ${ }^{41}$ and lawn-mower repair shops. They would leave some bikes for the manager of the store to play around with for a few weeks and then talk business afterward. $^{42}$

Motorcycles were not attractive objects in the American cultural mindset of the mid- $20^{\text {th }}$ century. The machines themselves often leaked oil, and they were widely considered the implements of delinquency. Marlon Brando, for instance, rode a motorcycle in 'The Wild One', in which he played the leader of a gang responsible for disturbing the quiet of a small, California town. ${ }^{43}$ In an effort to change the prevailing perception of motorcycles, Honda sponsored an ad-campaign with the tagline, 'You meet the nicest people on a Honda'. The advertisements themselves depicted ordinary folks - families and friends - going about day-to-day activities on Honda's models. Although the campaign proved wildly successful, the committee responsible for it was initially divided on the decision in 1963 . The director of sales had to persuade the more senior president - Kawashima himself - and treasurer, both of whom favored a competing advertising proposal. ${ }^{44}$

\footnotetext{
${ }^{39}$ Interviews with Kawashima and Kobayashi make it clear that the events were close in time but do not clarify whether recall of the larger models took place before or after Honda was approached by this prospective distributor. If after, Kawashima's restraint in taking advantage of available opportunities is accentuated. Even if before, though, considering that traditional distribution outlets had turned down the Super Cub and assuming that the offer was to sell this very model, it is clear that Kawashima exercised a degree of restraint.

${ }^{40}$ Kobayashi, Founding American Honda.

${ }^{41}$ Kawashima, Honda Motor Company Retrospective and Oral History (50-197 side-A\&B), 14.

42 Borin, "Enter Honda," 76.

${ }^{43}$ Sanders, Honda, 97.

${ }^{44}$ Pascale, "Perspectives on Strategy," 56; Kawashima, Honda Motor Company Retrospective and Oral History (50-196 sideA\&B), 27.
} 
There were other important advertising decisions for Kawashima to make in the early years of American Honda. He made the $\$ 80,000$ decision to place a one-page ad in LIFE magazine in 11 states. $^{45}$ Grey Advertising, the agency that had sold Honda 'the nicest people' campaign, requested that they sponsor the Academy Awards when it became clear that the campaign was resonating with consumers. ${ }^{46}$ The cost was upwards of 300,000 dollars a minute, which gave Kawashima pause. In hindsight, he recalled doubting very much whether he would have made the decision if it had been his own money, but he agreed to commit the funds and take on the mitigated, but significant, professional risk for his decision.

Kawashima also presided over American Honda when it began demanding payment from dealers before releasing motorcycles to them. American Honda may never have formally sold motorcycles on consignment, ${ }^{47}$ but in their earliest years they would willingly advance goods before payment. ${ }^{48}$ While some sources suggest the decision came about more quickly, ${ }^{49}$ according to Kawashima, the demand for cash-on-delivery was made in $1964 .{ }^{50}$ However early the decision was made, Kawashima (who departed for Japan only in 1965) ${ }^{51}$ was undoubtedly the head of American Honda and was stationed in America. Reports of the effects of the decision vary, ${ }^{52}$ but some sources claim that Honda's dealers were upset by the decision and that, though none did, that several threatened to drop Honda. ${ }^{53}$

\section{[III] The Debate: Literature on the History of Honda}

Histories of American Honda scrutinize how its leadership made choices. In particular, the case study has been used as a datum in debates over strategic decision-making and whether strategy in real world organizations is developed in a deliberate or emergent fashion. A choice is an array of alternatives confronting an agent endowed with the ability to select between them according to his or her will. A

\footnotetext{
${ }^{45}$ Kawashima, Honda Motor Company Retrospective and Oral History (50-196 side-A\&B), 18.

${ }^{46}$ Ibid., 27.

${ }^{47}$ Kobayashi, Founding American Honda.

${ }^{48}$ Dreyer, American Honda's early relationship with distributors; Borin, "Enter Honda," 73-74.

${ }^{49}$ Dreyer, American Honda's early relationship with distributors.

${ }^{50}$ Pascale, "Perspectives on Strategy," 56; Shook, "Honda Comes to America," 35; Honda Motor Co. Ltd, "Honda Annual Report 1964."

${ }^{51}$ Kawashima, Honda Motor Company Retrospective and Oral History (50-140 side-A), 4.

${ }^{52}$ Dreyer, American Honda's early relationship with distributors.

${ }^{53}$ Pascale, "Perspectives on Strategy"; Shook, "Honda Comes to America."
} 
strategy is the collection of those selections realized from choices pertinent to the activities and transactions of a firm. ${ }^{54}$ Deliberate strategies are those in which selections are "realized as intended" and emergent strategies are those in which selections are "realized despite, or in the absence of, intention". 55,56 Intentions may vary across parties in an organization, and so the characterization of a strategy as deliberate or emergent depends on identification of a focal agent. ${ }^{57}$ In the case of the Honda Motor Company, as made clear in the discussion to follow, the agent of interest is either Honda's upper management in general or Honda's chief strategist, Takeo Fujisawa, in particular.

The literature features roughly three positions on how best to categorize American Honda's decision-making process. The BCG report suggests, as do Prahalad and Hamel, that American Honda's strategy was deliberate - subordinate personnel made decisions according to the express intentions of upper management. In contrast, Pascale, Mintzberg, and Richardson argue that American Honda's strategy was emergent - decision outcomes were determined by happenstance and local circumstance rather than (or at times, as opposed to) the intentions of upper management. Subsequently, Rumelt, Mair, and Otahara have tempered these conclusions; their work suggests that Honda's strategy in America might be better described as both deliberate and emergent. Not all decisions are made in the same way and, indeed, different decisions may or may not be determined by managerial intentions.

In 1975, the British crown commissioned the Boston Consulting Group to explain the downfall of the British motorcycle industry. BCG reported evidence of a Japanese cost-advantage due to greater accumulated production during the 1960s but also suggested an explanation for how the organization had achieved this advantage. The consultants claimed to identify a Japanese 'marketing philosophy', or

\footnotetext{
${ }^{54}$ The choices given the greatest degree of scrutiny in this study - whether or not to demand cash-on-delivery and which firms to use as distributors - are rightfully considered strategic choices because they pertain to the transactions in which Honda participates.

${ }_{55}$ Mintzberg and Waters, "Of Strategies, Deliberate and Emergent," 257.

${ }^{56}$ In "Of Strategies, Deliberate and Emergent", 260, Mintzberg draws a distinction between deliberate strategy and a successful strategy. For a strategy to be deliberate, it must only satisfy the condition that selections are made according to the intentions of a given agent. It does not require the stronger condition to hold that the agent anticipate the effects of those decisions. While Section [VII] does consider the effects of decisions made by American Honda's management, the bulk of this study is focused on selections, not consequences.

${ }^{57}$ Ibid., 265. Mintzberg at times characterizes a strategy as deliberate or emergent with respect to different parties within the firm. An emergent strategy with respect to management might be a deliberate strategy with respect to employees, for example. In the case of Honda, the decisions might be more easily categorized as deliberate if the frame of reference is Kawashima, but that simply ignores the question of the appropriate categorization with respect to Fujisawa.
} 
emphasis on sales volume originating in a 'set of objectives" ${ }^{58}$ and extending through the operations of the firm. As evidence, the report presents the testimony of a personnel director who mentions that prospective dealers are asked about their share of the local market before being signed. The personnel director's admitted confusion at the extent of emphasis on sales volume suggests that he is merely obeying orders delivered by superiors. ${ }^{59}$ Because upper management intentions translate so clearly into subordinate behaviors, BCG's characterization of Honda's decision-making is best considered deliberate.

Prahalad and Hamel revisited the case of American Honda during the late 1980s while writing about business strategy in the Harvard Business Review. According to these authors, the success of contemporary Japanese firms, including Honda ${ }^{60}$ could be attributed to their 'strategic intent'. These firms, "sustained an obsession...for global leadership" and maintained "an active management process...motivating people by communicating the value of the target...[and] providing new operational definitions as circumstances change". ${ }^{61}$ Note that managers must observe the choices and circumstances facing employees and - to a first degree - develop intentions regarding those choices in order to nominate guiding criteria for decision-making. For this reason, it is fair to say that 'strategic intent' has instructional and not just motivational content. The decision-making process they claim to observe in Honda, therefore, is distinctly deliberate.

Pascale was the first to suggest that American Honda's strategy might be better described as emergent. Having studied patterns of Japanese management, ${ }^{62}$ Pascale was surprised by the suggestion in the BCG report that Honda exhibited a steadfast and premeditated commitment to sales volume. He

\footnotetext{
${ }^{58}$ Boston Consulting Group, Strategy Alternatives for the British Motorcycle Industry, 23.

${ }^{59}$ Ibid.

${ }^{60}$ It should be noted that the authors provide no empirical historical evidence defending their claims that strategy process in Honda was guided by 'strategic intent'. They write:

"When Honda took on leaders in the motorcycle industry, for example, it began with products that were just outside the conventional definition of the leaders' product-market domains. As a result, it could be a base of operations in underdefended territory and then use that base to launch an expanded attack. What many competitors failed to see was Honda's strategic intent... ... [E]ven as Honda was selling 50cc motorcycles in the United States, it was already racing larger bikes in Europe - assembling the design skills and technology it would need for a systematic expansion across the entire spectrum of motor-related businesses."

Of course, observing that Honda eventually expanded into other classes of motorcycle is not sufficient to conclude that management had, a priori, an intention to do so. In fact, evidence presented by Pascale suggests no such assuredness of eventual success.

${ }^{61}$ Prahalad and Hamel, "Strategic Intent."

${ }^{62}$ Pascale, The Art of Japanese Management, 91.
} 
convened the founders of American Honda in 1984 to interview them about their experiences. These officials were quick to admit that they had few instructions from Fujisawa about how to operate in America when they arrived in Los Angeles. ${ }^{63}$ They noted that consumer interest prompted them to promote the Super Cub rather than upper management, who had expected larger models to sell well in America. ${ }^{64}$ Finally, the successful 'Nicest People' advertising campaign in 1963 was supported by American Honda's then head of sales against the objections of more senior members of the organization. ${ }^{65}$ This evidence suggested that upper management contributed to Honda's success in the States by permitting subordinates to take advantage of perceived opportunities, rather than enforcing intentions.

Pascale's reinterpretation of Honda's history proved influential in an academic debate over how decision-making should be governed in a business organization. In this debate, Mintzberg was a vocal critic of what he called the 'planning school' and a proponent of the 'learning school'. The former approach prescribed the use of conceptual tools by upper management to make decisions and the subsequent use of organizational authority to ensure implementation by subordinates. ${ }^{66}$ The 'learning school', by contrast, suggested that upper management allow subordinates to act on intuition, provide resources to implement their decisions, and facilitate organization-wide adoption of best practices. Mintzberg was fully persuaded that American Honda's strategy was emergent: ${ }^{67}$

"Honda's success, if we are to believe those who did it and not those who figured it, was built precisely on what they initially believed to be [a] 'probable 'non-starter" - namely, the small motorcycle. Had they a proper planning process in place...this non-starter would have been eliminated at the outset." 68

He uses Pascale's evidence of upper management's preference for larger motorcycles to suppose counterfactually that planning would have been harmful to the Honda organization. This permits him to ground criticism of the 'planning school' in an historical example.

\footnotetext{
${ }^{63}$ Pascale, "Perspectives on Strategy," 54.

${ }^{64}$ Ibid., 54-55; Kawashima, Honda Motor Company Retrospective and Oral History (50-196 side-A\&B), 1.

${ }^{65}$ Pascale, "Perspectives on Strategy," 56; Kawashima, Honda Motor Company Retrospective and Oral History (50-196 sideA\&B), 27.

${ }^{66}$ Mintzberg, "The Design School."

${ }^{67}$ Mintzberg, Strategy Safari, 200-208.

${ }^{68}$ Mintzberg, "Learning 1, Planning 0.”
} 
Pascale's emphasis on the limited importance of upper management intentions has endured. As recently as 2011, Adam Richardson wrote a short article for the Harvard Business Review detailing 'Lessons from Honda's Early Adaptive Strategy'. He begins with the premise that Honda's success was the result of 'staying flexible to an emerging understanding of...opportunities'. He then revisits the most compelling examples offered by Pascale to demonstrate the opportunities that middle management observed and exploited and extracts colloquial messages from each for contemporary managers. ${ }^{69}$

Despite the influence of Pascale's analysis, recent work strives to reconcile his conclusions with the intentionality implied by the BCG report. When Richard Rumelt contributed to a 1996 retrospective on the Honda case, he observed limits to the evidence presented by both BCG and Pascale:

"The unfortunate fact is that the data provided by BCG and by Prahalad and Hamel are not sufficient to prove intentionality (it appears to be implicit in the writers' assumptions), and the data provided by Pascale are not sufficient to disprove the existence of a coherent logic covering the expansion of the motorcycle business from 1960 through 1980." ${ }^{.70}$

The strategy of American Honda was comprised of many decisions. According to Rumelt, even though Pascale demonstrated that strategic choices were initially emergent, this could have changed over time.

Reviewing the literature on Honda in 1999, Mair also attempted to reconcile opposing views on how the Honda organization made strategic decisions. He concluded that it was unsatisfactory to suppose that Honda's management made decisions based purely on design or on learning. He observes consensus in the literature, "...that in the Honda case it may not be appropriate to select among contending opposites [i.e. characterizations of strategy formulation]". ${ }^{71}$ And for this reason, he opines that "[i]t may therefore be high time to investigate whether managers at Honda have already been working within and refining [an alternative decision-making] paradigm for many years." ${ }^{, 72}$ This is presented as a concluding remark, however, and he does not clarify how Honda breaks from the deliberate-emergent mold.

More recently, Otahara has described an instance in which upper management did premeditate a choice and enforce their intentions in a way that contributed to the success of American Honda. Honda

\footnotetext{
${ }^{69}$ Richardson, "Lessons from Honda's Early Adaptive Strategy."

${ }^{70}$ Rumelt, "The Many Faces of Honda," 110.

${ }^{71}$ Mair, "Learning from Honda," 40.

${ }^{72}$ Ibid.
} 
opened a new factory facility with technology allowing for low-cost mass-production of the Super Cub in $1960 .^{73}$ This decision had been made by Fujisawa and Otahara evidences his aspirations to use the factory to be competitive on an international scene: "Being in a situation like this is an opportunity that does not come knocking often....By adding the Suzuka plant at this point we are in the process of forming opportunities for growing into an international Honda." ${ }^{, 74}$ Even if American Honda officials made decisions without heed of upper management intentions, contemporaneous decisions affecting American Honda's fortunes may well have been made deliberately, as this one was.

In this paper, following Pascale, we acknowledge that middle management did not receive input from upper management on how to go about making decisions - upper management intentions did not determine choice outcomes. We supplement the early history of American Honda's distribution channels with an investigation of Honda's distribution channels in Japan. This allows us to break from Pascale by asserting that precedent set by Fujisawa in Japan determined choice outcomes rather than happenstance or local circumstance. Though Fujisawa provided no instruction, his previous decisions provided a road-map that Kawashima turned to when making his own.

Our argument is thus similar in spirit to the more recent attempts at reconciling the emergent process suggested by Pascale's work with the deliberate one suggested by BCG's. Rumelt assigns emergent and deliberate strategy to different periods of history. Otahara's work establishes that different contemporaneous decisions affecting American Honda might be alternately emergent and deliberate. In this history, by contrast, it is individual choices that are characterized as both deliberate and emergent. Even when Fujisawa was uninformed about choices facing Kawashima and offered no input, Kawashima made decisions by following precedent. Therefore, though Honda's strategy in America emerged as Kawashima made decisions without Fujisawa so much as formulating an intention, these choices were nonetheless determined by hypothetical intentions that could be plausibly attributed to Fujisawa.

\footnotetext{
${ }^{73}$ Christiansen and Pascale, "Honda (B)," 3.

${ }^{74}$ Fujisawa as quoted in Otahara, "An Evolutionary Phase of Honda Motor," 128.
} 


\section{[IV] Appeal to Historical Precedent as a Decision-Making Protocol}

What protocols did management in the United States use to make decisions when faced with choices? In the case of deliberate strategy, managers might follow a plan authorized by or directives issued by superiors. Without the express intentions of upper management to guide decision-making, managers may proceed by exploiting sales opportunities or somewhat at random. In this section, we consider some of Kawashima's choices, introduced above in the outline of American Honda's history. We present evidence that various hypotheses regarding American Honda decision-making protocols are not satisfactory. And we conclude by suggesting an alternative: Kawashima followed the example of his mentor, Fujisawa.

Pascale was the first to note that senior management did not equip American Honda officials with any explicit plan before sending them off to explore a new market. In his interview with Kawashima, the latter recalled conversations with Fujisawa after a reconnaissance trip to the States in 1958, indeed after the decision to enter American markets had been made, but before returning more permanently to Los Angeles in 1959.

"In truth, we had no strategy other than the idea of seeing if we could sell something in the United States. It was a new frontier, a new challenge, and it fit the 'success against all odds' culture that Mr. Honda had cultivated. I reported my impressions to Fujisawa - including the seat-of-thepants target of trying, over several years, to attain a 10 percent share of US imports. He didn't probe that target quantitatively. We did not discuss profits or deadlines for breakeven. Fujisawa told me if anyone could succeed, I could and authorized \$1 million for the venture.,75

It seems Fujisawa was interested in neither Kawashima's tentative goal (10 percent market share) nor any intermediary steps that might be necessary to achieve this goal. Instead, he explicitly indicates that his confidence in the project is due to his faith in the skill of his subordinate.

Pascale was right to conclude that management in the United States did not make decisions according to a plan of action - taking Kawashima at his word, no such plan existed. But Fujisawa may have been all talk in giving Kawashima his blessing; despite his express confidence, he might have issued directives intervening with the operations of American Honda. Takayuki Kobayashi, who had accompanied Kawashima on the reconnaissance trip to America as his assistant and returned to American

\footnotetext{
${ }^{75}$ Pascale, "Perspectives on Strategy," 54.
} 
Honda for its first two years as the head of sales, insists that this was not the case. According to his recollection, as a matter of practice, Fujisawa did not interfere with decision-making at American Honda:

"Fujisawa was in Japan, but he trusted us to make our own decisions, as we were the ones on-site and more familiar with details. Deciding on your own was Honda's corporate culture. Given that we had learned Honda philosophy, we did not need to consult with Fujisawa in making daily decisions. Every six months, Kawashima went back to Japan and met Fujisawa, so it could be that Kawashima reported and consulted Fujisawa on some issues. However, I do not recall any incident where there was any change in Kawashima's decisions or directions after he returned from his trip to Japan., ${ }^{, 76}$

During the early years, Fujisawa clearly maintained the confidence in Kawashima he had expressed before the latter departed for the states. He permitted his subordinate to make decisions autonomously and apparently without amendment. In particular, Kobayashi confirmed that Kawashima did not solicit the advice of Fujisawa when deciding not to work with department store Montgomery Ward. ${ }^{77}$ Kawashima himself confirms that Fujisawa acquiesced to the initial recommendation of a $\$ 1$ million budget, deferred to the unconventional decision to locate offices in LA rather than New York City, ${ }^{78}$ and supported the recall of faulty models in the face of dissent from other members of the Honda organization. ${ }^{79}$

This evidence makes clear that it is unsatisfactory to interpret decisions of Kawashima as obedience to orders or explicit advice from superiors. Neither is it wholly satisfactory to suppose that he made choices to exploit available sales opportunities. Kobayashi describes how American Honda struggled to find distribution options for the Super Cub before being approached by Montgomery Ward. And though the offer paled in comparison to what Honda eventually sold, the potential of the product was unclear at the time of the offer. In this case, Kawashima opted to forego a significant sales opportunity. The decision to demand cash-on-delivery was made after American Honda was better established and it did not ultimately prompt dealers to defect. Still, Kawashima recalls dealers becoming frustrated by the decision $^{80}$ and Honda's experiences in Japan (elaborated in the following section) corroborated the

\footnotetext{
${ }^{76}$ Kobayashi, Founding American Honda; see also Kawashima, Honda Motor Company Retrospective and Oral History (50-196 side-A\&B), 12.

${ }^{77}$ Kobayashi, Founding American Honda.

${ }^{78}$ Kawashima, Honda Motor Company Retrospective and Oral History (50-196 side-A\&B), 5.

${ }^{79}$ Ibid., 11.

${ }^{80}$ Shook, "Honda Comes to America," 35; Pascale, "Perspectives on Strategy," 56.
} 
possibility of backlash. In the case of the latter decision, then, Kawashima was at least willing to risk losing dealers and corresponding sales by refusing to advance goods.

Beyond the realized and anticipated effects of decisions, interviews provide some insight into the underlying rationale motivating the response to Montgomery Ward. ${ }^{81}$ Kawashima describes the decision as "persisting in our refusal to sell through an intermediary". Though unspecified, Kawashima is likely referring not to any intermediary between manufacturer and customer (Honda sold through many neighborhood dealerships, after all) but specifically to the large intermediaries between manufacturer and dealership. Kobayashi corroborates this point, recalling “...we did not want to rely on a big distributor. We wanted to be close to customers. Large distributors... would not act to meet manufacturer's needs." 82 As they recall their thought process, both focus on the position of the distributor in the supply chain. And though Kawashima and Kobayashi both mention that the offers were exclusive (suggesting sales exploitation considerations), Kawashima makes clear that “....as they would offer to sell a significant number of bikes, it did appear to be attractive in that sense" ${ }^{83}$ The rationale provided by both Kawashima and Kobayashi for declining the offer of Montgomery Ward corroborates the notion that, in this instance, they did not act to uncritically exploit a business opportunity.

In practice, America Honda officials were authorized to make decisions on the basis of their own judgment but did not always act to exploit available sales opportunities. As a remedy to the shortcomings of hypothesized decision-making protocols, we propose another: Kawashima, who had joined Honda in 1951, made decisions by appealing to the example of his boss and former mentor, Fujisawa, whose management techniques he observed while coming up the ranks in Japan. Appeal to precedent is, after all, a possible decision-making protocol; if available alternatives closely approximate those of a choice made previously by another agent, then that agent's selection can serve as a guide for one's own.

\footnotetext{
${ }^{81}$ No such self-reflection or assessment of rationale regarding the demand for cash-on-delivery is available in interviews with these actors.

${ }^{82}$ Kobayashi, Founding American Honda, 4.

${ }^{83}$ Kawashima, Honda Motor Company Retrospective and Oral History (50-197 side-A\&B), 23.
} 


\section{[V] Tailoring distribution channels in a young Japanese motorcycle market (1949-1958)}

Though appeal to historical precedent is a possible decision-making protocol, there is no a priori reason to believe that it was the one employed by Kawashima in the United States. Accounts of American Honda's management do not provide the historical context necessary to establish precedent. To elaborate decisions made by Fujisawa in Japan that could have served as precedent for Fujisawa, we draw on welldocumented facts of Honda's history and our own original research. We focus on the avoidance of large intermediaries and demand for cash-on-delivery because the discussion above renders them most in need of an alternative explanation. Specifically, he let go of early Honda client Kioritz, he bypassed traditional motorcycle dealers, and he later made repeated attempts to demand advance payment from this new sales network. Notably, historical evidence shows that Fujisawa pursued this agenda despite the short-term damage it did to Honda's sales network. We discuss the context of the Japanese motorcycle market and Honda's relationship with distributor Kitagawa to argue instead that Fujisawa's motivation was to secure reliable payment.

\section{[A] Precedent established by Fujisawa}

When Honda was still in the business of manufacturing engines to supply as components, much of its business came from Kioritz Agricultural Machinery, who used the engines to make generators. Kioritz was a large company - it was listed in the first section of the stock exchange - and it was generally well regarded. Though business with Kioritz was profitable for Honda, Fujisawa decided to terminate the relationship. According to Kawashima,

"His basic idea was that Honda had to follow Kioritz's production plan. If they changed their production plan, then Honda would have to give in to their plan and change our production plan. As in the case of the sales network, we did not want others to have the initiative. His idea was that we should stop doing business if Honda cannot take the initiative. That must have been a big decision to make." 84

Fujisawa's primary concern is that Kioritz has a greater degree of flexibility than other distributors in adjusting the number of engines it orders from Honda. Kioritz's interests in rival accounts certainly makes them less dependent on successful resale of these engines.

\footnotetext{
${ }^{84}$ Kawashima, Honda Motor Company Retrospective and Oral History (50-142 side-A\&B), 73.
} 
Fujisawa was similarly wary of the traditional motorcycle dealers in the Japanese market. There were only about $300-400^{85}$ such dealers in the early 1950 s and were in high demand from the many motorcycle manufacturers of the day. Honda had sold its "D-type" and "A-type" motorcycles through these outlets, but Fujisawa felt that Honda's designs had been treated dismissively, put wherever there happened to be room on the sales floor. ${ }^{86}$ In March 1952, Soichiro Honda completed the prototype of the 50cc "Cub Type F". This was the first realization of an appealing combination of power and size, which, when realized with significant technological advances in the Super Cub, would launch Honda onto the world state. Because the engine was powerful but small enough to be clipped to a bicycle frame, ${ }^{87}$ Fujisawa realized he could bypass traditional dealers and appeal to Japan's smaller but more numerous bicycle shops instead. ${ }^{88,89}$

As the Cub became a popular motorcycle, Fujisawa demanded that bicycle shop owners pay him in advance. Though some contend cash-on-delivery was the outcome of working through bicycle shops, a dealer working for Honda at the time made clear that advance payments were not required until 6-12 months after the Cub went on sale (and after orders for the Cub increased). He continues:

"Dealers in various parts of the country were now to be required to give advance payments to secure products for their dealerships, and so I had to pay them myself. This news hit me like a bolt from the blue, and I wasn't pleased. This was my incentive to begin producing my own motorcycle." $" 90$

Thus, not only was the decision to demand advance payment distinct from the decision to appeal to bicycle shop owners, but the latter also appears to have upset Honda's dealer network and hurt short-term sales.

\footnotetext{
85 “Honda Worldwide | History | Using Direct Mail to Develop Sales Outlets for the Cub F-Type / 1952”; Sakiya, Honda Motor, 84.

${ }^{86}$ Kawashima, Honda Motor Company Retrospective and Oral History (50-142 side-A\&B), 8 .

${ }^{87}$ Sakiya, Honda Motor, 83; Alexander, Japan's Motorcycle Wars, 121.

${ }^{88}$ Sakiya, Honda Motor, 84.

${ }^{89}$ Because Fujisawa stopped selling through the traditional, large motorcycle distributors, this decision serves as precedent for Kawashima's later refusal of the Montgomery Ward offer. In the same historical moment, however, Fujisawa opted in favor of reaching out to non-traditional retail spaces. Although not the analytical focus of this section, the latter decision could well have served as precedent for Kawashima when reaching out to sporting goods and fishing stores. For that matter, there is evidence to suggest that Fujisawa's management style guided Kawashima when he made decisions to advertise through Time and the Academy Awards. Though historical precedent could have served as a decision-making guide in these case, the fact that behavior exploits sales opportunities means that we cannot rule out autonomous opportunism as a decision-making protocol.

90 Alexander, Japan's Motorcycle Wars, 186-87.
} 
Even after the introduction of the Cub, Fujisawa continued to push Honda to demand cash-ondelivery. He used Honda's growing sales force to be closer in its scrutiny of clients and more persistent in its demand for advance payment. ${ }^{91}$ He also demanded cash-on-delivery for the Benly, a high-performance motorcycle that went on sale in August 1953, and the Juno, a scooter that went on sale in January $1954{ }^{92}$ This demand, however, continued to give dealers pause; after the Juno proved to be a failed product, Fujisawa opted not to demand cash-on-delivery when selling the Super Cub in Japan. ${ }^{93}$

The investigation of Honda's history in Japan helps to explain Kawashima's decision-making protocol. That is, when faced with options (to advance goods or not to advance goods, to accept or decline Montgomery Ward's offer), what steps did he follow in making a selection? Honda's history in Japan suggests that he at least could have made these decisions according to selections made by Fujisawa in similar contexts. Fujisawa repeatedly demonstrated a preference for smaller distributors and for demanding cash-on-delivery. Moreover, Fujisawa's willingness to sacrifice and incur backlash for his choices could have buoyed Kawashima in following his example under similarly adversarial circumstances.

[B] Motivations for the precedent established by Fujisawa

Fujisawa's preferences for smaller distributors and advance payment clearly did not stem from a desire to maximize sales in the short run. Instead, there is evidence that they stemmed from a desire for reliable sales and payment, which were hard to come by in Japan's chaotic young motorcycle industry of the late 1940s and early 1950s. Securing a reliable source of components (transmissions, engines, frames, seats, wheels and wire harnesses) could be a challenge for firms, ${ }^{94}$ but it could be equally challenging to secure reliable distribution channels. Suzuki Koji, president of Meguro Manufacturing of Tokyo, described how manufacturers sold their output:

"Dealers came to stay in local inns near the factory, scrambling for the products. 'No trial runs yet,' or 'The trial run was good ...' they shouted, and took the products home....At one time,

\footnotetext{
${ }^{91}$ Sakiya, Honda Motor, 73.

92 Ibid., 86.

${ }^{93}$ Kawashima, Honda Motor Company Retrospective and Oral History (50-142 side-A\&B), 14.

${ }^{94}$ Alexander, Japan's Motorcycle Wars, 92-96.
} 
there were sixty makers and over a hundred products involved in the melee [in the Kanto region alone]." 95

The process of selling completed motorcycles for distribution was disorganized and relied heavily on dealers chasing hot models.

In a marketplace of such fleeting relationships, manufacturers struggled to get paid for their goods, even when dealers agreed to market them. In Honda's early years, it was common for manufacturers to sell to dealers on a consignment basis. ${ }^{96}$ When manufacturers demanded cash deposits, they were often in small amounts. Dealers were known to pay with checks that bounced. And when bank drafts became available, dealers went so far as to forge counterfeit drafts in the amount of the required deposit, leaving the manufacturer empty handed. This could cost manufacturers millions of yen and contributed to the demise of some manufacturers like Monarch motors. ${ }^{97}$

After Fujisawa joined the Honda Motor Company in October $1949,{ }^{98}$ he encountered precisely the difficulty of obtaining payment from dealers. At the time, Honda produced one engine that was 98cc and another that was $50 \mathrm{cc}$. The latter could be fit onto a bicycle frame by Honda, but the former required a sturdier frame than the company was able to produce. Rather than assemble a bike in-house, Honda sold the engine to a distributor who bought a suitable frame from a rival company, Kitagawa. The distributor assembled the motorcycle and then sold it downstream. ${ }^{99}$ Though Honda delivered 100 engines per month to the distributor, Kitagawa had scaled back production and begun delivering only $50-80$ of the corresponding frames. Kitagawa received payments un-problematically but Fujisawa had a difficult time getting the distributor to pay for all the engines Honda had provided. ${ }^{100}$

Some important determinants of sales and payment reliability are revealed by the Kitagawa example that seem to inform Fujisawa's later decision-making. First, the distributor's interest in a rival account appears to have led them to change their production schedule. This is precisely the phenomenon

\footnotetext{
${ }^{95}$ Ibid., 181.

${ }^{96}$ Kawashima, Honda Motor Company Retrospective and Oral History (50-142 side-A\&B), 5.

${ }^{97}$ Alexander, Japan's Motorcycle Wars, 182.

${ }^{98}$ Ibid., 118.

${ }^{99}$ Sakiya, Honda Motor, 68.

${ }^{100}$ Ibid.
} 
of which Kawashima is wary when considering Kioritz and his frustrations with the large distributors stem from their rival interests in other motorcycle manufacturers. Secondly, when goods are advanced to distributors, remuneration need not follow the terms of agreement and may instead be determined at the discretion of the distributor. This is of course remedied by demanding payment up front.

Indeed, soon after Kitagawa altered its production schedule, Honda began manufacturing the “Dream Type D", a model of motorcycle with a frame suited to their larger $98 \mathrm{cc}$ engines. ${ }^{10102}$ No longer dependent on Kitagawa to sell their engines, Fujisawa forced distributors to choose: they could purchase either engines to pair with Kitagawa's frames or the Dream but not both. ${ }^{103}$ The Kitagawa design was popular and distributors did not want to choose; many dropped Honda in retaliation, forcing Honda to rebuild part of its sales network. ${ }^{104}$ But forcing the issue helped eliminate Kitagawa as a rival loyalty or interest of the distributors who chose the Dream. This decision was thus similar in spirit to the later pursuit of small distributors.

\section{[VI] 'What would Fujisawa do?'}

While it is clear that a precedent was available for Kawashima, it remains to be seen that he was aware of this precedent and invoked it when making decisions in the American context. We supplement the extant literature on the history of Honda with our own findings to substantiate both claims.

Kawashima worked directly under Fujisawa for many years, showed similarities in judgment to Fujisawa immediately prior to being sent abroad to found American Honda, and had intimate exposure to Fujisawa's decision-making process. His awareness of Fujisawa's decision-making habits leave us inclined to take him at his word when he attests that his decision-making protocol consisted of posing the question, 'what would Fujisawa do?'

Kawashima agreed to work for the Honda organization in 1951 after being impressed by Fujisawa's global aspirations. He worked under Fujisawa with other members of the sales team to

\footnotetext{
${ }^{101}$ Fujisawa was not responsible for the decision to integrate horizontally; he had arrived at Honda after the prototype for the frame had been built and just before production began. Therefore, he cannot be credited with equipping Honda with control of the supply of frames complementing Honda's 98cc engine. His decision regarding the conditions under which Honda would sell their self-assembled motorcycles is significant notwithstanding.

${ }^{102}$ Sakiya, Honda Motor, 67-68.

103 Ibid., 68.

104 Ibid., 72.
} 
develop and maintain distribution channels. ${ }^{105}$ In the late 1958, as the Honda organization considered international expansion, he was appointed head of a Special Planning Division responsible for considering which foreign markets to enter and how. ${ }^{106}$ Upon deciding to establish a wholly owned subsidiary in the United States, he was appointed by Fujisawa to head that subsidiary, ${ }^{107}$ in a decision sometimes attributed to the extent of his experience working under Fujsiawa. ${ }^{108}$

Indeed, by the time of his promotion, Kawashima was an active participant in the decisionmaking process and his judgment was fairly consonant with Fujisawa's, though the latter retained some formal decision-making authority. ${ }^{109}$ Kawashima recalls initiating the trip he took to America in 1958 after seeing a report by the Japanese Machine Federation outlining opportunities for Japanese manufacturers to compete successfully in the American motorcycle market.

"This [report] was the beginning of it all. When I read it I thought it was great....In my mind I was fully persuaded [by the report] that America would be the best place to export motorcycles to, but I couldn't be satisfied just with these materials, I wanted to go there and see for myself." 110

Though he ultimately suggested Honda enter markets in Southeast Asia first, Kawashima would certainly have understood the prospects of the American market that motivated Fujisawa to overrule his proposal.

Beyond recognizing the advantages of the American market, Kawashima favored Honda's chosen mode-of-entry. Rather than entering the US with a wholly owned subsidiary, Honda had the opportunity to work through Japanese trading companies - and ultimately opted to do so in some other foreign countries. ${ }^{111}$ Kawashima notes, however that "the idea of not using [Japanese] trading companies did not come from Fujisawa. Based on what we had learned from Fujisawa, we made our own judgment that we should not rely on trading companies". ${ }^{112}$ In particular, Kawashima was told the advantage of working through a general trading company was that "If [your motorcycles] are handled by a general trading

\footnotetext{
105 "Honda Worldwide | History | Using Direct Mail to Develop Sales Outlets for the Cub F-Type / 1952."

${ }^{106}$ Shook, "Honda Comes to America," 28.

107 "Honda Worldwide | History | Establishing American Honda Motor Co. / 1959"; Shook, "Honda Comes to America," 28.

${ }^{108}$ Shook, "Honda Comes to America," 28.

${ }^{109}$ Several informal histories of the Honda Motor Company misrepresent the relationship between Fujisawa and Kawashima at the time of the decision to enter foreign markets. In these histories he travels to foreign markets at Fujisawa's bidding rather than on the basis of his own judgment ("Establishing American Honda Motor Co."; Sakiya, Honda Motor, 120.) and his suggestion that Honda enter Southeast Asia is overruled (Sakiya, Honda Motor, 121; Shook, "Honda Comes to America," 28.) These details suggest he was an instrumental rather than collaborative force in the decision making process.

110 Otahara, "An Evolutionary Phase of Honda Motor," 121.

${ }_{111}^{111}$ Kawashima, Honda Motor Company Retrospective and Oral History (50-142 side-A\&B), 10-11.

${ }^{112}$ Ibid., 10.
} 
company, at times when sales are slack the company can assign the employees in charge of sales to other duties, and running costs will be minimal." Kawashima was critical of this purported advantage; he felt it showed "an attitude of selling motorcycles in spare time."113 This response is noteworthy for its distrust of rival accounts that might temper a distributor's commitment to Honda - a distrust held in common with Fujisawa himself.

The similarities between Kawashima's judgment and that of his boss were no coincidence.

Kawashima had significant exposure to Fujisawa's decision-making process and described what it was like working for him in the early years:

"He would carefully think about the possible challenges for two or three days before presenting the plan to us. Then he would see how we respond to his proposal, and if he thinks that we are not so responsive, then he would take it back and rethink the strategy....[I]t was a bit different from a consultation. I think what he was doing was that he would present his idea, and after he saw our responses, he would organize and refine the issue before making decisions. So it was not like, 'what do you think of this issue,' but rather something like, 'I am thinking of doing something like this...."."114

At this stage in their development, Fujisawa did not authorize subordinates to influence decision-making

outcomes. But he did create opportunities for them to observe him as he wrestled with a choice and encouraged them to exercise their judgment on his behalf nonetheless. Kawashima would therefore have witness of the appropriate decision in a given context.

The effect of this mentorship was profound. Kawashima willingly embraced Fujisawa's pedagogical influence even after authorized to exercise his judgment autonomously. He consciously appealed to Fujisawa's example:

"[W]henever I was about to do something, I would first think about what Fujisawa would do if he were in my place. My life in the subsequent years was all about, 'what would Fujisawa decide to do?"”115

\section{[VII] Sales crisis and the transition to larger models (1966-1972)}

American Honda faced an inventory crisis from 1966-1968, after Kawashima had returned to Japan. Officials contacted Fujisawa, who launched a coordinated effort to mitigate losses on unsold

\footnotetext{
${ }^{113}$ Otahara, “An Evolutionary Phase of Honda Motor," 122.

${ }^{114}$ Kawashima, Honda Motor Company Retrospective and Oral History (50-140 side-A), 8.

${ }^{115}$ Ibid.
} 
inventory and initiated the design of new motorcycle models that would better serve consumer demand.

There is no evidence to suggest that Kawashima made management decisions in anticipation of this distribution crisis. But his decisions - to the extent that they resembled those of Fujisawa's in effect arguably provided Fujisawa with more rapid and accurate information about changing consumer tastes. In short, decision-making by historical precedent contributed to the process of segment advance observed by the BCG as the basis of Honda's continued success.

Honda sales began to falter by the spring of 1966, when it became clear that the firm would not sell as many motorcycles in America as it had anticipated. The previous year, the firm maintained an average of 20,000 units a month; they now expected to sell 8,000 units in September and only 2,000 by the coming November. ${ }^{116}$ Eventually, sales of all models, including the blockbuster Honda 50, began to fall. ${ }^{117}$ American Honda motorcycle sales fell in both 1967 and 1968 and before beginning to recover (figure 3). ${ }^{118}$

Figure 3 American Honda Motorcycle Sales (1960-1972)

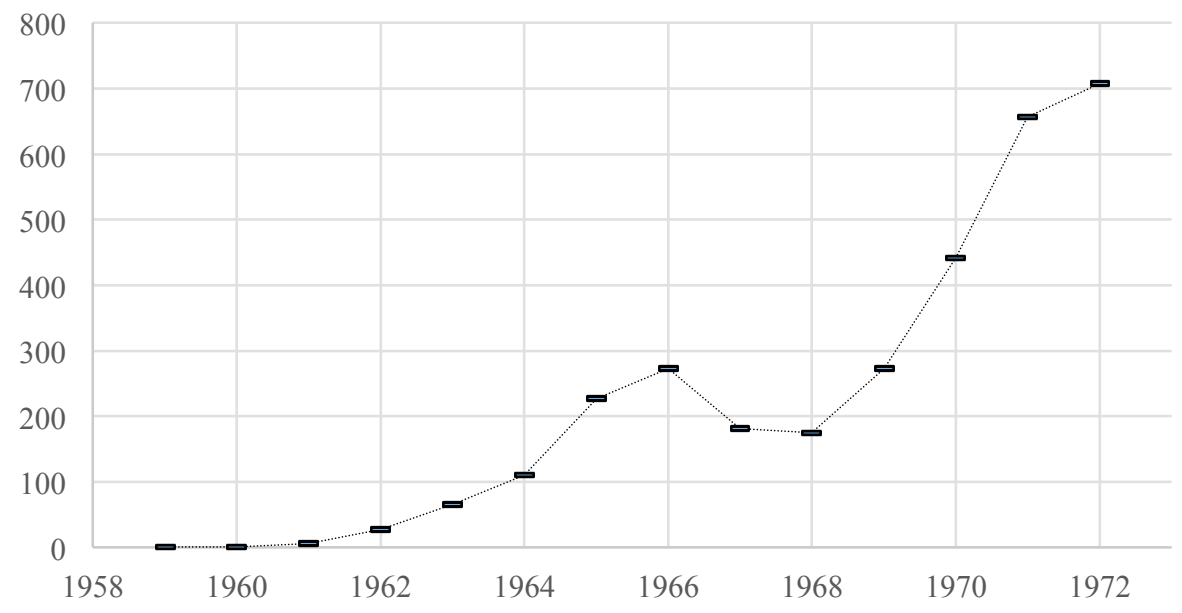

Source: Christiansen and Pascale, "Honda (B)", 9. ${ }^{119}$

Note: The sales of Honda motorcycles in the United States grew rapidly during the early 60 s and during the late 60 s and early 70s. However, Honda faced a considerable downturn in sales during the years 1967 and 1968.

\footnotetext{
${ }^{116}$ Sakiya, Honda Motor, 139.

${ }^{117}$ Ibid.; Kawashima, Honda Motor Company Retrospective and Oral History (50-197 side-A\&B), 19.

${ }^{118}$ Christiansen and Pascale, "Honda (B)," 9.

119 These figures are consistent with the size of the American market for motorcycles as recorded in Mito, Honda Book of Management, 38 .
} 
Honda's sales problem precipitated an inventory problem. The inflow of units from Japan exceeded the outflow to dealers it became expensive for American Honda to maintain their inventory. Honda officials in Japan reduced their export target from 450,000 to 360,000 during the 1966 fiscal year $^{120}$ to "cope with changes in the demand situation [in America]". ${ }^{121}$ By the end of the 1967 fiscal year, Honda reported that they had adjusted export shipments to decrease inventory levels being maintained in foreign markets. ${ }^{122}$ By the end of the 1968 fiscal year, the company reported that exports to the United States were recovering. ${ }^{123}$ But American Honda still had $\$ 80$ million tied up in 500,000 units. ${ }^{124}$

When the sales and inventory crises began in 1966, Kawashima was no longer present in Los Angeles to manage day-to-day operations; he had been promoted in 1965 to become one of Honda's managing directors. ${ }^{125}$ He acted only as American Honda Vice President, ${ }^{126}$ lived in Japan and only made occasional trips to check up on the subsidiary. ${ }^{127}$ For this reason, it was Fujisawa who was most immediately responsible for rescuing American Honda from the sales and inventory crisis it faced in the late 1960s. Kawashima had received word of rising inventory levels and contacted Fujisawa, who cut short a vacation to the Wagner music festival in Germany and flew to the States. ${ }^{128}$

The distribution channels as designed by Kawashima played a role in alerting Fujisawa to changing consumer tastes. When dealers can break contractual or verbal agreements without repercussion and are advanced goods before payment, they may err on the side of ordering units in excess of expected demand, knowing they need not repay debts in their entirety if strapped for cash. Under such an arrangement, inventory overseen by the manufacturer would propagate less quickly in response to falling demand. In the case of Honda motor, a delayed inventory crisis might have delayed managers at American Honda in contacting Fujisawa. Conversely, to the extent that large dealers with rival accounts (like department stores) face less cost than independent dealers in changing production schedules, they

\footnotetext{
${ }^{120}$ Barmash, "Increased Draft Quota Is Varied In Effect on Consumer Economy."

${ }^{121}$ Honda Motor Co. Ltd, "Honda Annual Report 1966."

${ }^{122}$ Honda Motor Co. Ltd, "Honda Annual Report 1967."

${ }^{123}$ Honda Motor Co. Ltd, "Honda Annual Report 1968."

${ }^{124}$ Sanders, Honda, 87; see also Mito, Honda Book of Management, 38.

${ }^{125}$ Honda Motor Co. Ltd, Honda Annual Report.

${ }^{126}$ Kawashima, Honda Motor Company Retrospective and Oral History (50-197 side-A\&B), 18.

${ }^{127}$ Kawashima, Honda Motor Company Retrospective and Oral History (50-140 side-A), 4.

${ }^{128}$ Sanders, Honda, 87; Kawashima, Honda Motor Company Retrospective and Oral History (50-197 side-A\&B), 19.
} 
may be more likely to do so for reasons other than changes in consumer demand. Accumulating inventory is therefore a more robust indicator of changing consumer tastes rather than disloyal distributors in the latter case. The decision to avoid large distributors and to demand cash-on-delivery, then, may well have improved information about demand available from observation of manufacturer inventory levels.

Once alerted, Fujisawa suggested improvements to the response plan proposed by ranking officials at American Honda. They intended to heavily discount prices to facilitate sales and reduce the expenses they bore to maintain inventory. But big discounts would sacrifice considerable revenue and would risk violating anti-dumping laws in the United States, so Fujisawa convinced officials to hold off. By extending Honda's credit line with the Mitsubishi bank and by slowing factory output in Japan, he gave them more time to sell off the inventory. With more time, discounts could be mitigated to improve the revenue taken on the existing models and, when the models became out dated at years end, discounts were legally less risky. ${ }^{129}$

Fujisawa noticed something else that American Honda's management had not - the plan to discount prices would solve the inventory crisis, but that the inventory problem was just a symptom. As he explained before leaving:

"This drop in sales owes to my inability to supply you with new models which were neglected because of Tokyo's self-conceit. Price cutting won't work because the real problem is unattractive current models. Don't worry about the inventory - somehow I'll manage to finance it on my return to Tokyo - but keep on trying to sell until we can get new models to you."130

Fujisawa explicitly observed a demand problem that would not be resolved by addressing growing inventory. As promised, upon returning to Tokyo, Fujisawa put pressure on engineers in Honda's R\&D department to develop new models. ${ }^{131}$

Though Fujisawa was undoubtedly right about the problem of underlying demand, there was speculation that consumer durables were all suffering as a result of macroeconomic fluctuation and the

\footnotetext{
${ }^{129}$ Sanders, Honda, 87; Sakiya, Honda Motor, 140.

${ }^{130}$ Sanders, Honda, 87.

131 "Honda Worldwide | History | Establishing American Honda Motor Co. / 1959."
} 
war in Vietnam. ${ }^{132}$ Were this the exclusive reason for falling demand, it would not have made sense for Fujisawa to expend resources developing new models of motorcycle. As it happened, though, Fujisawa was correct that consumers' tastes were beginning to change. Following the years of the sales crisis, the American motorcycle market grew more quickly in segments featuring larger motorcycles. By contrast, sales of bikes under $125 \mathrm{cc}$ (the class to which the Super Cub belonged) tapered and eventually fell (figure $4) .{ }^{133}$

Figure 4 The US Motorcycle Market (1968-1974) Growth in total units and by cc size class

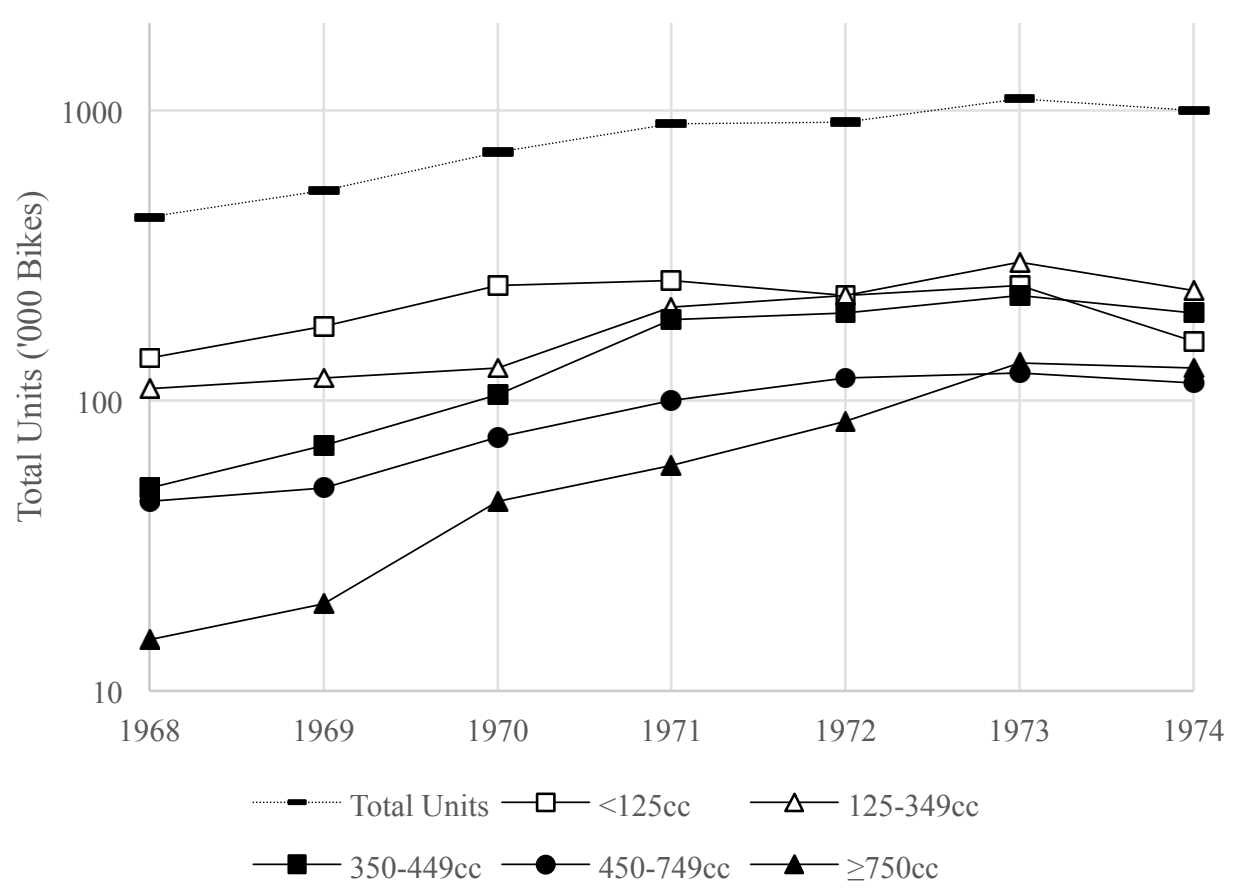

Source: Boston Consulting Group, Strategy Alternatives for the British Motorcycle Industry, 11.

Note: The graph above depicts the growth of the entire motorcycle market, sales from Honda as well as other manufacturers, from 1968 to 1974 . The steeper slopes associated with larger segments of the market make clear that the rate of growth of these segments was higher. It is also worthwhile to note that the $<125 \mathrm{cc}$ segment, which includes sales of the Honda 50 , tapered in growth and fell in 1972 and again, sharply, in 1974. This further suggests that growth in the industry was driven primarily by larger rather than smaller models.

Honda's continued success in the United States therefore depended on the development and sale of more traditionally-styled motorcycles. Indeed, in its 1968 corporate report, the firm notes that, “[m]otorcycle exports to the United States, where inventory adjustments have been completed, recovered

\footnotetext{
${ }^{132}$ Barmash, "Increased Draft Quota Is Varied In Effect on Consumer Economy"; Thomas, "Cycle Sales Find Road to Success a Bit Bumpy."

${ }^{133}$ Boston Consulting Group, Strategy Alternatives for the British Motorcycle Industry, 11.
} 
nicely with shipments of larger models rising especially fast". ${ }^{134}$ They do not elaborate which models specifically, but it is clear that the Supercub is not buoying sales alone. And in 1969, Honda released the CB750, the first model available with a mass-produced, four-cylinder, 750cc engine; it was accordingly inexpensive, smooth to ride, and powerful. ${ }^{135}$ A review in Cycle World reveals a new target audience for Honda:

"Tired of people not noticing? In past years, motorcycling marked you as a man apart. But now everyone rides a motorcycle, and things don't seem the same any more. The only thing that could relight your fire is the very best road bike in the world. Owning a bike like this, you could thumb your nose at the Honda Motor Company, which is most responsible for seeing that hordes of nouveau riders crowd you on your private road. But if you had the finest of all production machines, this two-wheeled answer to Ferrari-Porsche-Lamborghini, you would be riding a Honda 750cc four-cylinder. Soichiro-San would have the last laugh."136

Honda made its name in the American Market with the Super Cub, which cultivated a new market segment: economical transportation motorcycles for the ordinary user. But Honda rose from the ashes of its sales crisis recognizing the importance of claiming the prize segment so long defended by the British: recreational motorcycles for experts.

Although they sacrificed certain short-term sales opportunities, Kawashima's decision to demand cash-on-delivery and avoid large distributors contributed to the continued success of American Honda. His decisions themselves were not the product of chance or good fortune - they were consciously imitative - but it is worth adding that the effect of these decisions was not serendipitous either. In Japan, Fujisawa refused to advance goods because of dealers were fickle with payment ex post and he avoided large distributors because their rival accounts made them change distribution schedules. By eliminating the ability to be fickle in payment, Kawashima compelled distributors to consider seriously the level of demand ex ante. And by choosing smaller distributors, Kawashima ensured that changes in production would reflect changes in demand. The combined effect was to give Fujisawa better information about changing consumer tastes.

\footnotetext{
${ }^{134}$ Honda Motor Co. Ltd, "Honda Annual Report 1968."

${ }^{135}$ Brown, Honda, 46-49.

${ }^{136}$ Ibid., 48.
} 


\section{[VIII] Conclusion}

This history describes the management of American Honda by investigating the origin and consequences of distribution decisions. We focus on Kawashima's decision to decline Montgomery Ward and demand cash-on-delivery. By revisiting Honda's earlier history in Japan, we argue we argue that Kawashima's operative decision-making protocol was an appeal to historical precedent. By considering Honda's sales crisis in the late 1960s, we argue that the decision-outcomes realized through this protocol helped facilitate the segment advance that secured American Honda's leadership in the United States. Jointly, these arguments supplement a historical literature on the managerial determinants of American Honda's success, one that has wrestled with whether American Honda's early strategy is best characterized as deliberate or emergent. Reconciling opposing points of view, we argue that - as it pertains to certain decisions - Kawashima felt directed by Fujisawa's intentions despite the fact that Fujisawa never expressed any.

In a broader sense, this paper extends the literature that seeks to divulge the origin of intentions realized in strategy. Previous literature has suggested that intentions may originate in the will of individuals at various rungs of the organizational hierarchy. This paper suggests that the intentions governing strategy may instead originate in the imagination of an employee, as she hypothesizes the intention of a manager or mentor. As described in the introduction, this poses a problem for the characterization of strategy as either deliberate or emergent. The intentions that govern strategic choices may be hypothetical but made credible by comparison to historical precedent, that is, something in between the categories proposed by Mintzberg.

Describing the empirically observable decision-making processes within the firm is a legitimate scientific pursuit. Doing so productively, however, requires adequate conceptual tools and categorization schemes. If there are shortcomings to a typology that describes strategic decisions as merely intended or unintended, an alternative classification scheme may provide clarity. In this history, it was helpful to instead identify the party authorized to make a decision and the decision-rule employed. In cases of deliberate strategy, decision-making authority will rest with upper management. In cases of emergent 
strategy, their subordinates will exercise decision-making authority opportunistically or in an experimental fashion. In intermediate cases like Honda, subordinates may have decision-making authority but opt to follow historical precedent as a decision-rule.

It would be worthwhile to pursue several extensions and criticisms of this study. This essay focused on a limited number of managerial decisions made by Kawashima in order to address each rigorously. It could be revealing to systematically map the elements of Kawashima's management style to Fujisawa's tutelage. In particular, American Honda and its dealers faced a number of antitrust suits during the 1960 s, in which they were said to have colluded on resale prices. Our research uncovered no information linking Kawashima to this practice, but it worth noting that Fujisawa successfully introduced a single nationwide price for a model of motorcycle in 1957 in Japan, where it was legal. ${ }^{137}$ If there were evidence to suggest that Kawashima himself played a role in collusion with dealers, this essay suggests a reinterpretation of events: the posture was imitative rather than anticompetitive.

Second, this study staked the limited empirical claim that middle managers sometimes make decisions based on hypotheses about intentions of their superiors. The extent of the claim is limited, on the one hand, by its generalizability; only two managerial choices were actually audited. It would be worthwhile to consider whether managerial performance cannot be systematically evaluated to determine the prevailing decision-making protocols. On the other hand, the extent of the claim is limited by not addressing processes underlying the observed phenomenon. At first blush in the case of Honda, it appears that genuine commitment to the company and belief in Fujisawa's wisdom is what motivates Kawashima to tailor his actions in this way. But there might be different motivating circumstances, like the threat of termination or certain reward systems. It would be helpful to learn to distinguish between different candidate explanations.

Acknowledging the considerable room to extend this study's conclusions, it seems nonetheless plausible that decision-making by precedent is prevalent in business practice. For one, managers well intentionally promote subordinates who have quickly taken to their own repertoire of techniques. One

${ }^{137}$ Kawashima, Honda Motor Company Retrospective and Oral History (50-143 side-A\&B), 6. 
source indicated that this was possibly a reason for Kawashima's promotion. Moreover, to the extent that subordinates know this to be the case, they may seek to cultivate the instincts of managers well-positioned to offer them promotion.

\section{References}

Alexander, Jeffrey W. Japan's Motorcycle Wars: An Industry History. Honolulu: University of Hawaii Press, 2009.

Andrews, Kenneth Richmond. The Concept of Corporate Strategy. Custom ed. Burr Ridge, Ill: Irwin Custom Pub, 1987.

Ansoff, H. Igor. Strategic Management. New York: Wiley, 1979.

Baker, Ted, Anne Miner, and Dale Eesley. "Improvising Firms: Bricolage, Account Giving and Improvisational Competencies in the Founding Process." Research Policy 32, no. 2 (February 2003): 255-76.

Barmash, Isadore. "Increased Draft Quota Is Varied In Effect on Consumer Economy: Effect of Draft on Sales Varies." New York Times. June 19, 1966, sec. Business \& Finance.

Borin, Eliot. "Enter Honda." The Motorcyclist, July 1987.

Boston Consulting Group. Strategy Alternatives for the British Motorcycle Industry: A Report. Reports and Parers - House of Commons ; 532. London: Her Majesty's Stationery Office, 1975.

Bower, Joseph L. "Chapter 2: Findings." In Managing the Resource Allocation Process, 30-65, n.d.

Brown, Roland. Honda: The Complete Story. Paperback ed. Crowood MotoClassics. Wiltshire England: Crowood, 1998.

Burgelman, Robert A. "A Process Model of Internal Corporate Venturing in the Diversified Major Firm." Administrative Science Quarterly 28, no. 2 (June 1983): 223-44.

Chandler, Alfred D. (Alfred Dupont). Strategy and Structure: Chapters in the History of the Industrial Enterprise. Cambridge, Mass: MITPress, 1975.

Chia, Robert, and Robin Holt. "Strategy as Practical Coping: A Heideggerian Perpective." Organization Studies (01708406) 27, no. 5 (May 2006): 635-55.

Christiansen, Evelyn T., and Richard T. Pascale. "Honda (A) and (B) Teaching Note." Harvard Business School Cases, April 12, 2011.

Christiansen, Evelyn T., and Richard Tanner Pascale. "Honda (A)." Harvard Business School Cases, August 1983, 1. "Honda (B)." Harvard Business School Cases, August 1983, 1.

Coase, Ronald. "The Nature of the Firm." In The Firm, the Market, and the Law, 33-55. The University of Chicago Press, 1988.

Denrell, Jerker, Christina Fang, and Sidney Winter. "The Economics of Strategic Opportunity." Strategic Management Journal 24 (2003): 977-90.

Dreyer, Mike. American Honda's early relationship with distributors, March 10, 2016.

Hambrick, Donald C., and Phyllis A. Mason. "Upper Echelons: The Organization as a Reflection of Its Top Managers." Academy of Management. The Academy of Management Review (Pre-1986) 9, no. 2 (April 1984): 193.

Honda Motor Co. Ltd. Honda Annual Report. Continued By: Annual Report / Honda Motor Co. Ltd. Tokyo, 1963.

"Honda Annual Report 1964," n.d. Historical Corporate Report Collection: AJI Nomoto Company, Inc. - Hooker Corp. Ltd. HBS Archives - Baker Library. Accessed July 31, 2015. "Honda Annual Report 1966," n.d. Historical Corporate Report Collection: AJI Nomoto Company, Inc. - Hooker Corp. Ltd. HBS Archives - Baker Library. 
“Honda Annual Report 1967," n.d. Historical Corporate Report Collection: AJI Nomoto Company, Inc. - Hooker Corp. Ltd. HBS Archives - Baker Library.

"Honda Annual Report 1968," n.d. Historical Corporate Report Collection: AJI Nomoto Company, Inc. - Hooker Corp. Ltd. HBS Archives - Baker Library.

"Honda Worldwide | History | Establishing American Honda Motor Co. / 1959." Accessed May 25, 2016. http://world.honda.com/history/challenge/1959establishingamericanhonda/index.html.

"Honda Worldwide | History | Using Direct Mail to Develop Sales Outlets for the Cub F-Type / 1952." Accessed May 25, 2016. http://world.honda.com/history/limitlessdreams/ftype/index.html.

Jarzabkowski, Paula. "Shaping Strategy as a Structuration Process." Academy of Management Journal 51, no. 4 (August 2008): 621-50.

Kato, Toshihiko, Tsuyoshi Numagami, Masaru Karube, and Masato Sasaki. "Types of Upward Communication and Organizational Characteristics in Japanese Firms." HitotsubashiJournal of Commerce and Management 47, no. 1 (October 2013): 1-16.

Kawashima, Kihachiro. Honda Motor Company Retrospective and Oral History (50-140 side-A), 1998. . Honda Motor Company Retrospective and Oral History (50-142 side-A\&B), 1998. . Honda Motor Company Retrospective and Oral History (50-143 side-A\&B), 1998. . Honda Motor Company Retrospective and Oral History (50-196 side-A\&B), 1998. . Honda Motor Company Retrospective and Oral History (50-197 side-A\&B), 1998.

Kobayashi, Takayuki. Founding American Honda, July 16, 2015.

Mair, Andrew. "Learning from Honda." Journal of Management Studies 36, no. 1 (January 1999): 25-44.

Miner, Anne S., and David F. Robinson. "Organizational and Population Level Learning as Engines for Career Transitions." Journal of Organizational Behavior 15, no. 4 (July 1994): 345-64.

Mintzberg, Henry. "Learning 1, Planning 0: Reply to Igor Ansoff. (Research Notes and Communications)." Strategic Management Journal 12, no. 6 (1991): 463.

. "Patterns in Strategy Formation." Management Science (Pre-1986) 24, no. 9 (May 1978): 934.

. Strategy Safari: A Guided Tour through the Wilds of Strategic Management. New York: Free Press, 1998.

."The Design School: Reconsidering the Basic Premises of Strategic Management." Strategic Management Journal 11, no. 3 (1990): 171-195. doi:10.1002/smj.4250110302.

Mintzberg, Henry, and James A. Waters. "Of Strategies, Deliberate and Emergent." Strategic Management Journal 6, no. 3 (July 1, 1985): 257-72. doi:10.1002/smj.4250060306.

Mito, Setsuo. Honda Book of Management. Bloomsbury Academic, 2013.

Moorman, Christine, and Anne Miner. "Organizational Improvisation and Organizational Memory." The Academy of Management Review 23, no. 4 (October 1998): 698-723.

Otahara, Jun. “An Evolutionary Phase of Honda Motor.” Japanese Yearbook on Business History 17 (2001): 109-135.

Papadakis, Vassilis M., Spyros Lioukas, and David Chambers. "Strategic Decision-Making Processes: The Role of Management and Context." Strategic Management Journal 19, no. 2 (February 1998): 115-47.

Pascale, Richard T. "Perspectives on Strategy: The Real Story behind Honda's Success." California Management Review : CMR 26, no. 3 (1984): 47-72. The Art of Japanese Management: Applications for American Executives. New York: Simon and Schuster, 1981.

Prahalad, Gary, and C. K. Hamel. "Strategic Intent.” Harvard Business Review. Accessed May 29, 2015. https://hbr.org/2005/07/strategic-intent.

Richardson, Adam. "Lessons from Honda's Early Adaptive Strategy." Harvard Business Review. Accessed May 28, 2015. https://hbr.org/2011/02/lessons-from-hondas-early-adap.

Rivkin, Jan W. "Honda (A) and (B) Teaching Note (II)." Harvard Business School Cases, February 9, 2006.

Rumelt, Richard P. “The Many Faces of Honda.” California Management Review 38, no. 4 (Summer 1996): 103-11. 
Sakiya, Tetsuo. Honda Motor: The Men, the Management, the Machines. Translated by Kiyoshi Ikemi. Updated pbk. ed. Tokyo: Kodansha International ; New York, 1987.

Sanders, Sol W. Honda: The Man and His Machines. 1st Tuttle ed. Rutland, Vt; Tokyo, Japan: Tuttle, 1977.

Satō, Masaaki. The Honda Myth: The Genius and His Wake. 1st American ed. New York: Vertical, 2006.

Shook, Robert L. "Honda Comes to America." In Honda: An American Success Story, 1st ed., 28-35. New York: Prentice Hall, 1988.

Thomas, Bob. "Cycle Sales Find Road to Success a Bit Bumpy." Los Angeles Times (1923-Current File). April 9, 1967, sec. G.

Tsoukas, Haridimos. "Practice, Strategy Making and Intentionality: A Heideggerian onto-Epistemology for Strategy as Practice." In Cambridge Handbook of Strategy as Practice, 47-62. Cambridge University Press, n.d. Accessed April 22, 2016.

Vera, Dusya, and Mary Crossan. "Improvisation and Innovative Performance in Teams." Organization Science 16, no. 3 (2005): 203-24.

Whittington, Richard. "Completing the Practice Turn in Strategy Research." Organization Studies (01708406) 27, no. 5 (May 2006): 613-34.

Williamson, Oliver. "Hierarchical Control and Optimum Firm Size." Journal of Political Economy 75, no. 2 (April 1967): 123-38.

Woolridge, Bill, and Steven Floyd. "The Strategy Process, Middle Management Involvement, and Organizational Performance.” Strategic Management Journal 11 (1990): 231-41. 